\title{
Carcinoma Erysipelatoides Resulting from Gastric Adenocarcinoma: An Unusual Clinical Presentation
}

\author{
${\text { Halil Kavgacia }{ }^{a} \text { Abdulkadir Reis }}^{b}$ Feyyaz Ozdemir ${ }^{a}$ Ozlem Bektas ${ }^{c}$ \\ Mehmet Arslan ${ }^{d}$ Fazil Aydin ${ }^{a}$
}

Departments of a Oncology, ${ }^{\mathrm{b} P a t h o l o g y},^{\mathrm{c}}$ Internal Medicine, and d Gastroentrology, Faculty of Medicine, Karadeniz Technical University, Trabzon, Turkey

\section{Key Words}

Carcinoma erysipelatoides · Stomach adenocarcinoma • Laryngeal skin

\begin{abstract}
Objective: To report a rare case of carcinoma erysipelatoides on the laryngeal skin caused by stomach adenocarcinoma. Clinical Presentation and Intervention: A 48year-old male, who had undergone a gastrectomy 18 months prior to admission for stage IIIA gastric adenocarcinoma, presented with a reddish induration of the cervical skin, lymphadenopathy in both supraclavicular areas and widespread subcutaneous nodules. Abdominal computerized tomography and chest radiography did not reveal any organ metastasis or peritoneal carcinomatosis. A biopsy of the induration revealed atypical epithelial cells with edema and dilatation of lymphatics. The patient was given combination chemotherapy of etoposide, adriamycin, and cisplatin, and significant improvement was observed over the cervical area after three courses. The patient tolerated the systemic chemotherapy well and has been followed for two months. Conclusion: We recommend combination chemotherapy in patients with cutaneous metastasis of gastric adenocarcinoma as a safe and effective treatment.
\end{abstract}

Copyright @ 2005 S. Karger AG, Basel

\section{Introduction}

Gastric carcinoma is a common malignancy worldwide [1]. Advanced disease can result in metastases to many areas of the body, most often the liver, lungs, bone, and adrenal glands [2]. Skin involvement in the form of subcutaneous nodules is not frequent, although Sister Mary Joseph's nodule is a well-known phenomenon [3].

An uncommon form of cutaneous metastasis is carcinoma erysipelatoides, which is generally caused by breast carcinoma and has rarely been linked to the primary cancers of other organs, except for some cases with pulmonary [4] and colon adenocarcinoma [5] and genitourinary cancer [6]. Carcinoma erysipelatoides caused by stomach adenocarcinoma is an extremely rare condition. As far as we know, only two cases of carcinoma erysipelatoides due to gastric adenocarcinoma have been reported so far [7, 8 ], and no case of carcinoma erysipelatoides on cervical skin due to gastric adenocarcinoma has been reported yet.

We report an unusual case of erysipelatoid metastasis to the cervical skin in a 48-year-old patient who had been diagnosed with stage IIIA gastric adenocarcinoma and had undergone a gastrectomy 18 months prior to presentation.
Ass. Prof. Dr. Halil Kavgaci

Faculty of Medicine, Karadeniz (Black Sea) Technical University

Department of Oncology

TR-61080 Trabzon (Turkey)

Tel. +90 4623775413, Fax +90 4633272270, E-Mail hkavgaci@meds.ktu.edu.tr 
Fig. 1. Macroscopic feature of carcinoma erysipelatoides on cervical skin.
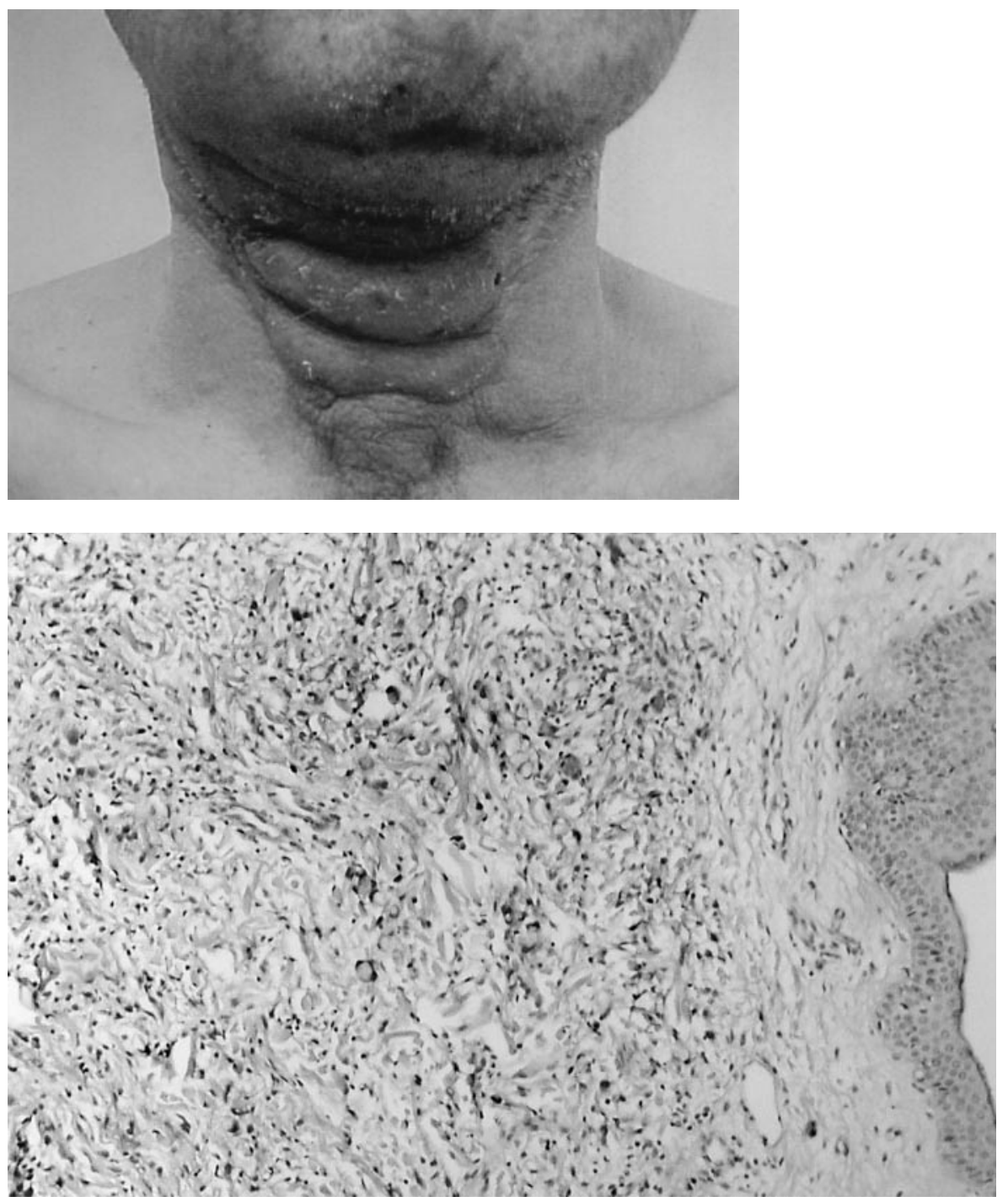

Fig. 2. Tumoral cell infiltration in dermis with edema and dilatation of lymphatics (large arrow) and signet ring cells (small arrow). HE. $\times 200$.

The patient had received 6 courses of etoposide, adriamycin, and cisplatin (EAP) chemotherapy after gastrectomy, and this same treatment was administered upon histological confirmation of skin metastasis. Significant cutaneous improvement was observed over the cervical area after 3 courses of chemotherapy. He tolerated the chemotherapy very well and has been followed for 2 months.

\section{Discussion}

Cutaneous metastasis from internal cancers is uncommon and usually due to melanoma, lung, breast, or colon cancer [3]. In 7,316 non-melanoma cancer patients, less than $1 \%$ of patients had cutaneous metastases at the time 
of diagnosis [9]. As with other remote metastasis, skin metastasis due to gastric cancer shortens survival of the patient. A patient administered intralesional interleukin2 died within 2 months of treatment [8], but another patient responded well to systemic chemotherapy and had a long survival [10]. Although our patient has been followed for only 2 months, he has tolerated the systemic chemotherapy well without any compromise.

\section{Conclusion}

We recommend combination chemotherapy in patients with cutaneous metastasis of gastric adenocarcinoma as a safe and effective treatment.

\section{References}

1 Pallio D: Epidemiology of gastric cancer: An evaluation of available evidence. J Gastroenterol 2000; 12:84-89.

2 Stefanini M: Adenocarcinoma of the stomach: An update. Compr Ther 1988;24:582-589.

3 Leffell DJ, Carucci JA: Management of skin cancer; in DeVita VT, Hellman S, Rosenberg SA (eds): Cancer: Principles and Practice of Oncology, 6th edition. Philadelphia, Lippincott Williams \& Wilkins, 2001, pp 1976-2002.

$\checkmark 4$ Hazelrigg DE, Rudolph AH: Inflammatory metastatic carcinoma: Carcinoma erysipelatoides. Arch Dermatol 1997;113:69-70.
Weeb JM: Carcinoma erysipelatoides from the colon. J Am Acad Dermatol 1996;34:10821084.

6 Elston DM, Tuthill RJ, Pierson J, Marden JD, Bergfeld WF: Carcinoma erysipelatoides resulting from genitourinary cancer. J Am Acad Dermatol 1996;35:993-995.

7 Han MH, Koh GJ, Choi JH, Sung KJ, Koh JK, Moon KC: Carcinoma erysipelatoides originating from stomach adenocarcinoma. J Dermatol 2000;27:471-474.
Hamamato Y, Nagai K, Ichimiya M, Yamamato K, Kinoshita E, Muto M: Regressive effect of intralesional injection of a moderate dose of recombinant interleukin-2 on carcinoma erysipelatoides from gastric carcinoma. Clin Exp Dermatol 2000;26:42-44.

-9 Lookingbill DP, Spangler N, Sextom FM: Skin involvement as the presenting sign of internal carcinoma. J Am Acad Dermatol 1990;22:1921.

10 Michiwa Y, Earashi M, Kobayashi H, Matsuki $\mathrm{N}$ : Cutaneous metastases from gastric adenocarcinoma treated with combination chemotherapy producing complete response with long survival. J Exp Clin Cancer Res 2001;20:297299. 